\title{
Effect of Road Traffic Noise Pollution on Human Work Efficiency in Government Offices, Private Organizations, and Commercial Business Centres in Agartala City Using Fuzzy Expert System: A Case Study
}

\author{
Debasish Pal and Debasish Bhattacharya \\ Department of Mathematics, National Institute of Technology Agartala, Jirania 799055, India \\ Correspondence should be addressed to Debasish Bhattacharya, debasish_pl@rediff.com
}

Received 15 November 2011; Revised 25 July 2012; Accepted 10 October 2012

Academic Editor: Madan M. Gupta

Copyright ( 2012 D. Pal and D. Bhattacharya. This is an open access article distributed under the Creative Commons Attribution License, which permits unrestricted use, distribution, and reproduction in any medium, provided the original work is properly cited.

\begin{abstract}
This study examines the problems of reduction of individual's efficiency in his/her respective working places because of road traffic noise pollution in Agartala due to rapidly growing vehicular traffic. This paper deals with monitoring and modeling of the disturbances caused due to vehicular road traffic interrupted by traffic flow conditions on personal work performance. Total of two hundred seventy individuals from different road side Government Offices, Private Organizations and Commercial Business Centres on both sides of busy roads of the city were interviewed for attitudinal responses. Traffic volume count and noise indices data were collected simultaneously at six selected sites of the city. A relationship was developed between different traffic noise parameters and its harmful impact on work competency of individuals using MATLAB. Regression equations developed to predict the percentage of high annoyance among the individuals are fit based on noise parameters and parameters related to traffic movements. In addition, statistical analysis was also carried out between measured and predictive values of the percentage of highly annoyed group of individuals. The present model will draw the attention of the State Government and will help the policy maker to take the necessary steps to reduce this problem.
\end{abstract}

\section{Introduction}

Noise pollution [1] is a significant environmental problem in rapidly developing built-up cities like Agartala. Traffic noise [2] is probably the most rigorous and pervasive type of noise pollution. Traffic noise has become a serious problem nowadays because of inadequate urban planning of the city in the past. Homes, schools, offices, hospitals, commercial business centers, and other community buildings were routinely built close to the main roads of the municipality without buffer zones or adequate sound proofing. The problem has been compounded by increases in traffic volumes (two wheelers, heavy motor vehicles, and other vehicles) far beyond the expectations of our early urban planners. This alarming increase in the volume of traffic is actually inversely related to the degradation of the environment [3]. Noise pollution is one of the major environmental pollutants that are encountered in daily life and has direct effects on human performance. Sound pressure is a basic measure of the vibrations of air that makes up sound, and because the range that the human listeners can detect is very wide, these levels are measured on the logarithmic scale with units of decibel (dB). Agartala, capital of Tripura, is a relatively medium-large urban city, situated in the North-Eastern region of India, is located at $23.50^{\circ} \mathrm{N}$ and $91.5^{\circ} \mathrm{E}$. As per 2011 census, the population of Agartala city has exceeded 5,12,000 (Agartala Municipality Statistics, provided by the $A M C$ (Agartala Municipal Council) at the Government of Tripura website.)

1.1. Objectives of the Study. The objectives of the study were as the following. 
(i) To assess the impact on human work efficiency due to road traffic parameters, different noise indices, and attitudinal response.

(ii) To study the temporal pattern of road traffic in the study area.

(iii) To study the existing status of noise levels in the study area by recording the noise intensity at various locations.

(iv) Identification and consideration of suitable mitigation and abatement measures.

For this, the study was conducted at three levels. The first level predicts the percentage of high annoyance (\%HA) among the individuals in terms of various noise indices like day-night noise level $\left(L_{\mathrm{dn}}\right)$, traffic noise Index (TNI), equivalent noise level $\left(L_{\mathrm{eq}}\right)$, and maximum equivalent noise Level $\left(L_{\max }\right)$. The second level describes the percentage of high annoyance (\%HA) in terms of average traffic volume, percent of two wheelers, percent of heavy vehicles, and mean traffic speed. The third level describes the percentage of high annoyance (\%HA) based on Quis model. All of the three models mentioned above are regression models. In the statistical analysis part, the correlation coefficients between the observed values and the values obtained by three models are calculated separately. We also studied the goodness of fit between the observed and the estimated values obtained from the three models individually using paired $t$-test. The $t$-statistics are given by

$$
t=\frac{\bar{d}}{S / \sqrt{n-1}},
$$

where $\bar{d}$ and $S$ denote, respectively, the mean and standard deviation of the differences $d_{i}$, that is, $\bar{d}=\sum d_{i} / n ; S^{2}=$ $\sum\left(d_{i}-\bar{d}\right)^{2}=\sum d_{i}^{2} / n-\left(\sum d_{i} / n\right)^{2}$. Under the null hypothesis that the means of the observed and the expected data are equal, the statistic follows $t$-distribution with $(n-1)$ degrees of freedom.

1.2. Review of the Literature. Recent researches clearly demonstrate that road traffic noise has been the predominant source of annoyance; no other single noise has been of comparable importance. It is due to the large number of automotive vehicles in comparison with other machines. In India, few studies on a traffic noise level have been carried out in different cities like Calcutta, Delhi, Bombay, Visakhapatnam, Baroda, Anantpur, Asansol, and so forth [4-9]. In international arena, recent works on the traffic noise assessment have been carried out in different cities like Alexandria, Tehran, and so forth $[10,11]$.

1.3. Scope and Structure of the Study. The study presents the problem of this noise pollution in terms of road traffic. The study starts with a background cover of noise pollution, its effect among the individuals, and the literature review with similar works around the world and also in India. The main portion of the work includes monitoring by field data collection method, prediction by modeling, and

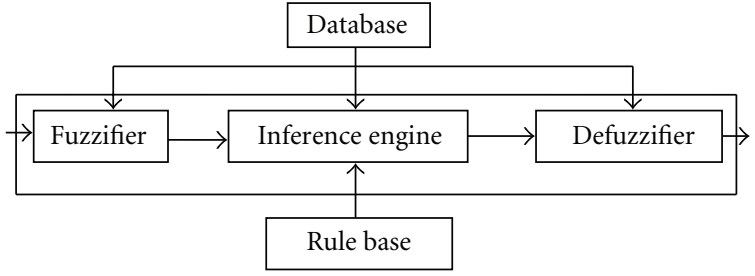

Figure 1: Structure of fuzzy expert system.

identification of the spread and distribution of the data. The present study was developed to collect environmental data in relation to road traffic noise by methods of monitoring and storing them for further retrieval, editing, and analysis and promoting their use for the best possible purpose.

\section{Fuzzy Modeling}

The concept of fuzzy modeling was originally proposed [12] and developed further by other researchers [13, 14]. The model proposed by [15] is based on the collections of IFTHEN rules with both fuzzy antecedent and consequent predicates. The advantage of this model is that the rule base is generally provided by an expert. Hence to a certain degree it is transparent to interpretation and analysis. The fuzzy system is an expert knowledge-based system that contains the fuzzy algorithm in a simple rule-based. As depicted in Figure 1, a fuzzy system is composed of four parts: fuzzifier, knowledge base, inference engine, and defuzzifier. The fuzzifier converts real-valued inputs into fuzzy values. The knowledge base includes fuzzy rule base and database. Membership functions of the linguistic terms are contained in the database. The inference engine calculates fuzzy output from fuzzy inputs using fuzzy implication function, and finally the defuzzifier yields a real-value output from the inferred fuzzy output [16].

\section{Survey Techniques}

Sound level meter, model SL-4001, was used to measure the noise level. The range and sensitivity of the instrument is from $30 \mathrm{~dB}(\mathrm{~A})$ to $80 \mathrm{~dB}(\mathrm{~A}), 50 \mathrm{~dB}(\mathrm{~A})$ to $100 \mathrm{~dB}(\mathrm{~A})$, and $80 \mathrm{~dB}(\mathrm{~A})$ to $130 \mathrm{~dB}(\mathrm{~A})$ with accuracy [+ or - ] 5\% (web reference) [17]. The noise level was recorded from road side offices, organizations, and commercial business centers which are at distances depending on location of the building from the center of the road, located at different places of Agartala. Motor vehicular traffic-prone selected sites of the town are Office Lane, Mantri Bari Road, Ronaldsay Road, Akhaura Road, Hari Ganga Basak (H.G.B.) Road, and Central Road which are representatives of the entire urban areas. All these sites have their unique characteristics that is, having a typical road width, roadside building pattern, and traffic flowing pattern in different directions. At each selected sites, noise levels have been measured at six different spots. At each spot, the measurements were taken at an interval of $2 \mathrm{hrs}$ during day time ( 8 AM-8 PM). During the measurements in a particular slot, the average of 5 frequent readings noted at 


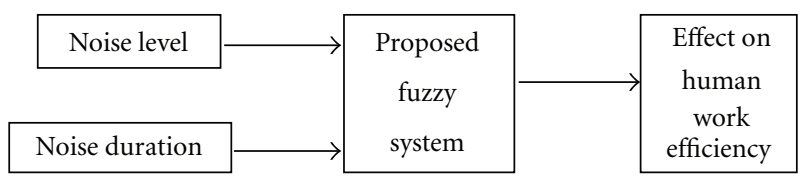

FIGURE 2: Fuzzy model for expert system.

TABLE 1: Input variables and output variable with their fuzzy values.

\begin{tabular}{|c|c|c|c|}
\hline $\begin{array}{l}\text { System's } \\
\text { variable }\end{array}$ & $\begin{array}{l}\text { Linguistic } \\
\text { variables }\end{array}$ & $\begin{array}{l}\text { Linguistic } \\
\text { values }\end{array}$ & $\begin{array}{c}\text { Fuzzy } \\
\text { intervals }\end{array}$ \\
\hline \multirow{8}{*}{ Input } & \multirow{5}{*}{ Noise level } & L: low & $35-55 \mathrm{~dB}(\mathrm{~A})$ \\
\hline & & M: medium & $50-70 \mathrm{~dB}(\mathrm{~A})$ \\
\hline & & $\mathrm{H}$ : high & $65-85 \mathrm{~dB}(\mathrm{~A})$ \\
\hline & & VH: very high & $80-100 \mathrm{~dB}(\mathrm{~A})$ \\
\hline & & EH: extremely high & $95-115 \mathrm{~dB}(\mathrm{~A})$ \\
\hline & \multirow{3}{*}{ Noise duration } & Short & 0-8 hour \\
\hline & & Medium & $7-16$ hour \\
\hline & & Long & 14-24 hours \\
\hline \multirow{7}{*}{ Output } & \multirow{7}{*}{ Annoyance } & ES: extremely small & $0-0.2$ \\
\hline & & VS: very small & $0.15-0.35$ \\
\hline & & S: small & $0.30-0.50$ \\
\hline & & M: medium & $0.45-0.65$ \\
\hline & & H: high & $0.60-0.80$ \\
\hline & & VH: very high & $0.75-0.95$ \\
\hline & & EH: extremely high & $0.9-1$ \\
\hline
\end{tabular}

a pause of $30 \mathrm{sec}$ is taken as the representative of the noise level of that slot. To the perception about the noise and its significance on work performance, a representative sample of 270 individuals was interviewed for attitudinal responses in the city.

\section{Methodology and Materials}

The methodology used in the design of the present fuzzy expert system is explained by the following algorithm.

(i) The present fuzzy system has two input variables and one output variable as shown in Figure 2; only those inputs, which affect the output to a large extent, have been selected.

(ii) The input variables and output variable with their linguistic values and fuzzy intervals are shown in Table 1.

(iii) By using MATLAB, a total of 15 relationships (IFTHEN rules) between input and output variables are formed. These rules are illustrated as the following.

(1) If (Noise level is Low) and (Noise duration is Short) then (Effects on Human work efficiency is Extremely Small).

(2) If (Noise level is Low) and (Noise duration is Medium) then (Effects on Human work efficiency is Very Small).

(3) If (Noise level is Low) and (Noise duration is Long) then (Effects on Human work efficiency is Small).
(4) If (Noise level is Medium) and (Noise duration is Short) then (Effects on Human work efficiency is Very Small).

(5) If (Noise level is Medium) and (Noise duration is Medium) then (Effects on Human work efficiency is Small).

(6) If (Noise level is Medium) and (Noise duration is Long) then (Effects on Human work efficiency is Medium).

(7) If (Noise level is High) and (Noise duration is Short) then (Effects on Human work efficiency is Small).

(8) If (Noise level is High) and (Noise duration is Medium) then (Effects on Human work efficiency is Medium).

(9) If (Noise level is High) and (Noise duration is Long) then (Effects on Human work efficiency is High).

(10) If (Noise level is Very High) and (Noise duration is Short) then (Effects on Human work efficiency is Medium).

(11) If (Noise level is Very High) and (Noise duration is Medium) then (Effects on Human work efficiency is High).

(12) If (Noise level is Very High) and (Noise duration is Long) then (Effects on Human work efficiency is Very High).

(13) If (Noise level is Extremely High) and (Noise duration is Short) then (Effects on Human work efficiency is High).

(14) If (Noise level is Extremely High) and (Noise duration is Medium) then (Effects on Human work efficiency is Very High).

(15) If (Noise level is Extremely High) and (Noise duration is Long) then (Effects on Human work efficiency is Extremely High).

(iv) Finally, through questionnaire the attitudinal response of individuals has been collected and shown in Figure 3 (pie chart).

4.1. Noise Level Standards. The Central Pollution Control Board (CPCB) has notified ambient air-quality standards for noise (which has been included as an air pollutant under Section 20 of the amended Air Act of 1987) [18]. The permissible noise levels in commercial, residential, and silence zones during the day time are given in Table 2. The silence zone is defined as an area up to $100 \mathrm{~m}$ around such premises as hospitals, educational institutes, and courts. The use of vehicle horns, loud speakers, and bursting of crackers is to be banned in such zones.

The identified location for the field studies and their location code are placed in Table 3.

Various common noise percentile values $L_{10}, L_{50}, L_{90}, L_{\mathrm{eq}}$, and $L_{\max }$ were recorded (using Sound Level Meter, model SL4001) for the estimation of $\mathrm{L}_{d n}$ and TNI. The TNI is a method 
TABLE 2: Ambient noise standards prescribed by CPCB.

\begin{tabular}{lcc}
\hline Silence zone (low congested) & Residential area (medium congested) & Commercial area (heavy congested) \\
\hline Office Lane & Ronaldsay Road & Hari Ganga Basak Road \\
Mantri Bari Road & Akhaura Road & Central Road \\
Permissible noise level: $50 \mathrm{~dB}$ (A) & Permissible noise level: $55 \mathrm{~dB}$ (A) & Permissible noise level: $65 \mathrm{~dB}$ (A) \\
\hline
\end{tabular}

TABLE 3: Identified locations for the field studies.

\begin{tabular}{lc}
\hline Location place & Location code \\
\hline Office Lane & L1 \\
Mantribari Road & L2 \\
Ronaldsay Road & L3 \\
Akhaura Road & L4 \\
H.G.B. Road & L5 \\
Central Road & L6 \\
\hline
\end{tabular}

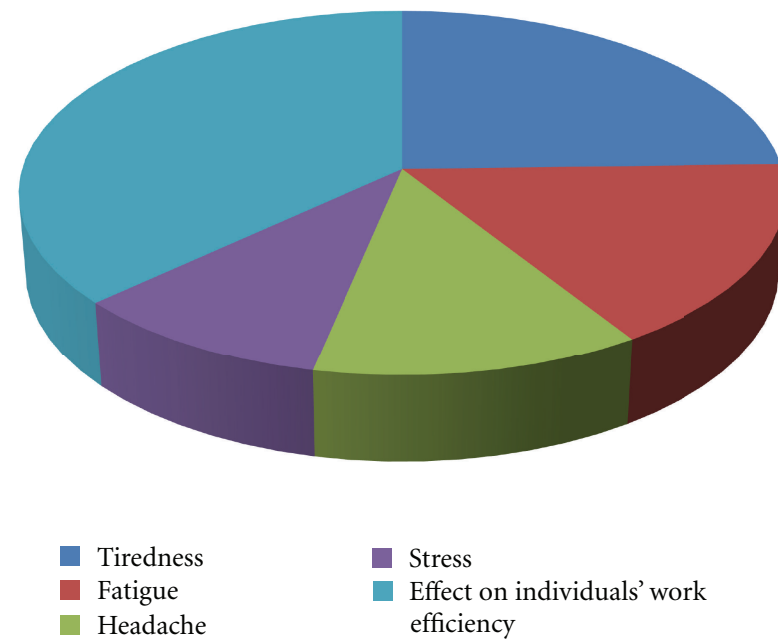

FIgUre 3: Attitudinal response of individuals.

used for the estimating annoyance responses due to traffic noise and is computed using the following formula [19]:

$$
\mathrm{TNI}=4\left(L_{10}-L_{90}\right)+\left(L_{90}-30\right),
$$

where $L_{10}=$ level of sound exceeded for $10 \%$ of the total time of measurement and $L_{90}=$ level of sound exceeded for $90 \%$ of the total time of measurement.

While the $L_{\mathrm{dn}}$ is a 24-hour average noise level used to define the level of noise exposure on a community, it can be calculated by the following formula [20]:

$$
L_{\mathrm{dn}}=10 \log \left\{\frac{1}{24}\left[15\left(10^{L_{\mathrm{d}} / 10}\right)+9\left(10^{L_{\mathrm{n}}}+10\right) 10\right]\right\} \text {, }
$$

where $L_{\mathrm{d}}=$ equivalent noise levels during day time and $L_{\mathrm{n}}=$ equivalent noise levels during night time.

Different traffic characteristics like traffic volume count including percentage of two wheelers, percentage of heavy motor vehicles, the percentage of other vehicles, and average traffic speed were also recorded. A comprehensive, yet briefstructured, questionnaire was made to find information about traffic noise traits and its effects on exposed individuals. For data collection a "Simple Random Sampling" technique was used on the local area population of the selected sites of the city. 45 individuals were selected at each site for Random Sampling Questionnaire and total 270 individuals (persons working at the business centers and offices of the identified sites) were interviewed at six selected locations. Traffic noise levels and traffic volume count were also recorded at identifying locations.

\section{Results and Discussion}

The study area is subjected to problems encountered due to pressure of rapidly increasing and unplanned traffic volume. The roads in the study area have been observed to be overflown with voluminous traffic throughout the day. The results of observation and field data are analyzed and discussed in this section. Through questionnaire, the attitudinal response of individuals has been collected and it is clear that they are facing some major problems like headache, effect on work efficiency, less concentration, fatigue, stress, and tiredness during the time period $8 \mathrm{AM}-8 \mathrm{PM}$ (Figure 3, pie chart).

Table 4 shows that the average noise level at Office Lane ranged between 67.82 and $73.28 \mathrm{~dB}(\mathrm{~A})$.

Table 5 indicates that the noise level at Mantri Bari Road recorded between 68.33 and $72.23 \mathrm{~dB}(\mathrm{~A})$.

The average noise level at Ronaldsay Road recorded between 76.65 and $80.56 \mathrm{~dB}(\mathrm{~A})$ and the average noise level ranging between 77.06 and $79.73 \mathrm{~dB}(\mathrm{~A})$ at Akhaura Road are shown in Tables 6 and 7, respectively.

The average noise level ranging between 86.98 and $92.15 \mathrm{~dB}(\mathrm{~A})$ at Hari Ganga Basak Road and 88.12 and $92.86 \mathrm{~dB}(\mathrm{~A})$ at Central Road are shown in Tables 8 and 9, respectively. Use of horns and traffic congestion is the main cause of noise pollution in these areas.

Table 10 shows that the percent of high annoyance among the targeted individuals due to road traffic were between 23.57 and $30.12 ; L_{\mathrm{dn}}$ value ranged between 72.52 and 75.98; $L_{\max }$ (instantaneous sound level) was ranged between 76.80 and 97.68 , whereas TNI was ranged between 91.75 and 95.88 . High noise levels and annoyance values were due to overpopulated road ways with bad conditions, broken roads, minimal traffic management, and frequent misuse of horns at all the selected sites. Improper stoppage of public transportation facilities also increases the congestion level. 
Table 4: Noise levels in dB (A) at Office Lane.

\begin{tabular}{lccccccccc}
\hline Sl. no. & I & II & III & IV & V & VI & Average & Max. & Min. \\
\hline 1 & 70.9 & 72.8 & 80.5 & 78.2 & 65.1 & 72.2 & 73.28 & 80.5 & 65.1 \\
2 & 68.1 & 65.6 & 75.2 & 70.5 & 67.4 & 71.6 & 69.73 & 75.2 & 65.6 \\
3 & 74.2 & 68.1 & 62.3 & 71.5 & 66.5 & 73.5 & 69.35 & 74.2 & 62.3 \\
4 & 68.2 & 74.3 & 75.6 & 77.3 & 64.4 & 70.2 & 71.66 & 77.3 & 64.4 \\
5 & 60.4 & 68.7 & 72.6 & 62.3 & 76.4 & 66.5 & 67.82 & 76.4 & 60.4 \\
6 & 72.2 & 76.2 & 65.6 & 68.7 & 73.4 & 68.2 & 70.72 & 65.6 & 73.4 \\
\hline
\end{tabular}

Table 5: Noise levels in dB (A) at Mantri Bari Road.

\begin{tabular}{lccccccccc}
\hline Sl. no. & I & II & III & IV & V & VI & Average & Max. & Min. \\
\hline 1 & 73.2 & 81.3 & 67.1 & 62.2 & 72.1 & 77.5 & 72.23 & 81.3 & 62.2 \\
2 & 65.6 & 76.2 & 68.3 & 65.4 & 75.5 & 72.2 & 70.53 & 76.5 & 65.4 \\
3 & 70.1 & 76.4 & 68.5 & 71.2 & 63.4 & 70.2 & 69.96 & 76.4 & 63.4 \\
4 & 74.5 & 66.1 & 70.5 & 71.2 & 68.8 & 67.5 & 69.77 & 74.5 & 66.1 \\
5 & 62.4 & 68.2 & 72.8 & 76.5 & 67.6 & 65.5 & 68.83 & 76.5 & 62.4 \\
6 & 64.3 & 72.5 & 62.2 & 68.4 & 74.2 & 68.4 & 68.33 & 74.2 & 62.2 \\
\hline
\end{tabular}

TABLE 6: Noise levels in dB (A) at Ronaldsay Road.

\begin{tabular}{lccccccccc}
\hline Sl. no. & I & II & III & IV & V & VI & Average & Max. & Min. \\
\hline 1 & 79.2 & 70.2 & 81.5 & 76.5 & 72.2 & 80.3 & 76.65 & 81.5 & 70.2 \\
2 & 76.5 & 83.4 & 80.1 & 70.8 & 75.5 & 78.2 & 77.42 & 83.4 \\
3 & 82.3 & 78.2 & 86.5 & 80.2 & 74.3 & 76.5 & 79.66 & 86.5 & 74.3 \\
4 & 78.3 & 85.5 & 77.2 & 82.1 & 76.1 & 84.2 & 80.56 & 85.5 & 76.1 \\
5 & 72.1 & 76.5 & 78.2 & 78.7 & 82.2 & 81.2 & 78.15 & 82.2 & 72.1 \\
6 & 80.2 & 76.7 & 82.1 & 80.7 & 72.4 & 77.1 & 78.20 & 82.1 & 72.4 \\
\hline
\end{tabular}

Table 7: Noise levels in dB (A) at Akhaura Road.

\begin{tabular}{lccccccccc}
\hline Sl. no. & I & II & III & IV & V & VI & Average & Max. & Min. \\
\hline 1 & 80.1 & 72.2 & 70.1 & 81.2 & 82.2 & 76.6 & 77.06 & 82.2 & 80.1 \\
2 & 68.2 & 76.2 & 82.2 & 78.5 & 83.4 & 80.2 & 78.12 & 83.4 \\
3 & 86.3 & 78.5 & 80.7 & 74.5 & 77.2 & 81.2 & 79.73 & 86.2 \\
4 & 74.5 & 82.2 & 78.1 & 80.2 & 76.1 & 84.3 & 79.23 & 84.3 & 74.5 \\
5 & 82.3 & 81.5 & 78.3 & 68.7 & 80.3 & 76.1 & 77.80 & 82.3 \\
6 & 77.2 & 84.1 & 74.3 & 80.1 & 72.2 & 78.7 & 77.76 & 84.1 & 72.2 \\
\hline
\end{tabular}

Table 8: Noise levels in dB (A) at Hari Ganga Basak Road.

\begin{tabular}{lccccccccc}
\hline Sl. no. & I & II & III & IV & V & VI & Average & Max. & Min. \\
\hline 1 & 89.2 & 83.4 & 78.5 & 92.1 & 86.2 & 98.5 & 87.98 & 98.5 & 78.5 \\
2 & 86.2 & 92.6 & 82.1 & 97.4 & 94.2 & 100.4 & 92.15 & 100.4 & 82.1 \\
3 & 90.5 & 81.2 & 91.5 & 97.6 & 96.6 & 88.7 & 91.02 & 97.6 & 81.2 \\
4 & 80.1 & 87.1 & 94.5 & 86.7 & 101.5 & 90.2 & 90.02 & 101.1 & 80.1 \\
5 & 85.1 & 90.5 & 98.2 & 88.2 & 92.2 & 82.1 & 89.38 & 98.2 & 82.1 \\
6 & 92.4 & 88.1 & 95.2 & 84.5 & 78.2 & 83.5 & 86.98 & 95.2 \\
\hline
\end{tabular}

Using different sets of independent variables, three predictive models were developed for the calculation of the percentage of high annoyance among the individuals' in their respective working place. In the first set of data, noiserelated factors like $L_{\mathrm{dn}}$, TNI, $L_{\mathrm{eq}}$, and $L_{\max }$ were used as independent variables and a regression equation was given as follows:

$$
\begin{aligned}
\% \mathrm{HA}_{1}= & 0.097871 L_{\mathrm{dn}}+0.277972 L_{\max }-0.16978 \mathrm{TNI} \\
& +0.209855 L_{\mathrm{eq}}-0.987358
\end{aligned}
$$


TABLE 9: Noise levels in dB (A) at Central Road.

\begin{tabular}{lccccccccc}
\hline Sl. no. & I & II & III & IV & V & VI & Average & Max. & Min. \\
\hline 1 & 87.5 & 86.3 & 80.2 & 96.5 & 94.1 & 88.2 & 88.7 & 96.5 & 80.2 \\
2 & 92.2 & 84.1 & 90.1 & 98.2 & 102.5 & 90.1 & 92.86 & 102.5 & 84.1 \\
3 & 82.8 & 93.2 & 86.1 & 85.4 & 90.2 & 97.5 & 89.2 & 97.5 & 82.8 \\
4 & 90.1 & 97.2 & 88.2 & 80.4 & 96.1 & 100.5 & 92.08 & 100.5 & 80.4 \\
5 & 86.5 & 92.1 & 78.3 & 95.1 & 90.5 & 98.7 & 90.2 & 98.7 \\
6 & 92.2 & 82.5 & 90.1 & 86.6 & 94.1 & 83.2 & 88.12 & 94.1 & 82.5 \\
\hline
\end{tabular}

TABLE 10: Description of various parameters collected at each selected location.

\begin{tabular}{lcccccc}
\hline Site & Traffic & Sample & \multicolumn{2}{c}{ High } & \multicolumn{3}{c}{ Noise indices, dB (A) } \\
& condition & Size & annoyance $\%$ & $L_{\text {eq }}$ & $L_{\text {dn }}$ & $L_{\max }$ \\
\hline L1 & Low congested & 45 & 24.45 & 58.12 & 72.52 & 76.80 \\
L2 & Low congested & 45 & 23.57 & 59.52 & 73.96 & 79.05 \\
L3 & Medium congested & 45 & 26.46 & 62.34 & 75.15 & 83.53 \\
L4 & Medium congested & 45 & 28.42 & 61.86 & 72.87 & 87.26 \\
L5 & Heavy congested & 45 & 28.17 & 63.82 & 75.32 & 97.68 \\
L6 & Heavy congested & 45 & 30.12 & 63.56 & 75.98 & 97.68 \\
\hline
\end{tabular}

TABLE 11: Calculation of percentage of high annoyance (using regression equation (4)).

\begin{tabular}{lc}
\hline Site & $\begin{array}{c}\text { Percentage of high annoyance } \\
\text { (using regression equation }(4))\end{array}$ \\
\hline L1 & 23.56 \\
L2 & 24.66 \\
L3 & 26.42 \\
L4 & 27.88 \\
L5 & 31.08 \\
L6 & 30.79 \\
\hline
\end{tabular}

And using the regression equation (4) and Table 10, the percentage of high annoyance was calculated and shown in Table 11.

In the second case, average vehicles per hour $(Q)$, percent of heavy vehicles $\left(Q_{h}\right)$, percent of 2 -wheeler $\left(Q_{2 w}\right)$, and mean vehicular speed (Vs) were used as independent variables in regression analysis. The developed equation was given as follows:

$$
\begin{aligned}
\% \mathrm{HA}_{2}= & 34.232521+0.004705 Q+0.389752 Q_{\mathrm{h}} \\
& -0.086476 Q_{2 \mathrm{w}}-0.532284 \mathrm{Vs} .
\end{aligned}
$$

The percentage of high annoyance calculated by using (5) was shown in Table 12.

Also the percentage of high annoyance was calculated by using Quis model [3] as given below:

$$
\% \mathrm{HA}_{3}=0.24\left(L_{\mathrm{dn}}-42\right)+0.0277\left(L_{\mathrm{dn}}-42\right)^{2},
$$

where, $L_{\mathrm{dn}}=$ day-night equivalent noise levels and is shown in Table 13.

Predicted values \%HA were calculated using both regression models (i.e., (4) and (5)) and compared with observed

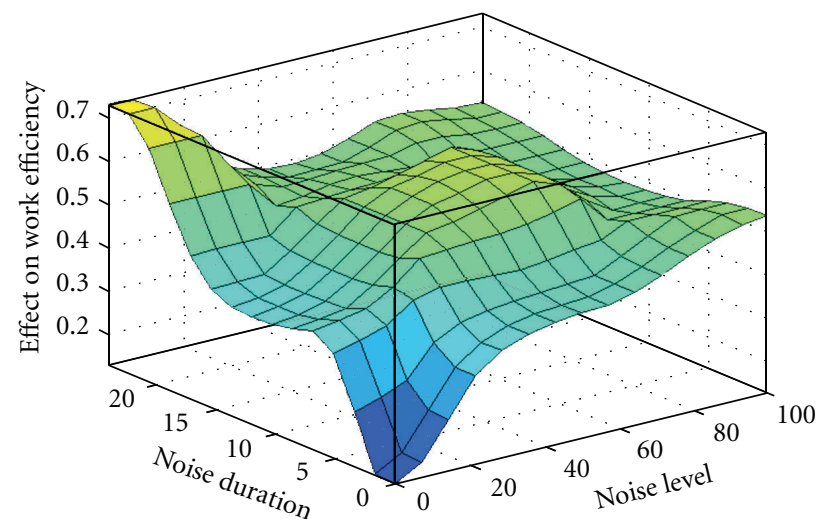

FIgURE 4: Relation between output variables (Effect on work efficiency) and input variables (Noise Level and Noise Duration).

values (collected from field survey). Further, observed values were also compared with the conventional Quis Model and the detailed results of statistical analysis for three models were shown in Table 14.

By fuzzy expert system and with the help of Table 1 and MATLAB 7.8.0., Mesh diagram (Figure 4) has been drawn, which represents the relationship between input variables and output variable.

5.1. Discussion on Findings. To evaluate the impact of road traffic noise on target individuals, the perception cum attitudinal study was conducted using a questionnaire method at six locations along with acoustic measurements. A total of 270 respondent's data was used for the analysis. Annoyance with the existing noise environment, as expressed by individuals at each site, was associated with the noise intensities in such a way that it was possible to predict the level of annoyance by taking into account the mean sound 
TABLE 12: Calculation of percentage of high annoyance (using regression equation (5)).

\begin{tabular}{lccccc}
\hline Site & $\begin{array}{c}\text { Average vehicles } \\
\text { per hour }(Q)\end{array}$ & $\begin{array}{c}\text { Percent of heavy } \\
\text { vehicles }\left(Q_{\mathrm{h}}\right)\end{array}$ & $\begin{array}{c}\text { Percent of } \\
\text { 2-wheeler }\left(Q_{2 \mathrm{w}}\right)\end{array}$ & $\begin{array}{c}\text { Mean vehicular speed } \\
(\text { Vs })\end{array}$ & $\begin{array}{c}\text { high annoyance \% } \\
\text { (using regression equation }(5))\end{array}$ \\
\hline L1 & 236 & 23.4 & 34.4 & 28.1 & 26.51 \\
L2 & 215 & 24.9 & 35.8 & 27.6 & 27.18 \\
L3 & 352 & 26.8 & 38.5 & 26.6 & 28.77 \\
L4 & 390 & 24.4 & 37.2 & 25.7 & 28.66 \\
L5 & 416 & 27.1 & 38.4 & 24.6 & 30.38 \\
L6 & 438 & 25.8 & 40.1 & 25.3 & 29.40 \\
\hline
\end{tabular}

TABLE 13: Calculation of percentage of high annoyance (using regression equation (6)).

\begin{tabular}{lc}
\hline Site & $\begin{array}{c}\text { Percentage of high annoyance } \\
\text { (using regression equation (6)) }\end{array}$ \\
\hline L1 & 33.80 \\
L2 & 35.96 \\
L3 & 33.12 \\
L4 & 41.36 \\
L5 & 45.03 \\
L6 & 38.74 \\
\hline
\end{tabular}

levels. The relationships were evaluated using correlation regression modeling. The important findings of this exercise are given hereunder.

(i) The consultations with doctors and analysis of audiogram results indicate that the most prevalent problems among those tested include irritation, headache, tinnitus, and sleeplessness, which ultimately have effects on human work efficiency on his/her respective working places.

(ii) It has been observed that all the three models show moderate-to-high degree of correlation between the observed value and estimated value. The noise-based model yields the highest correlation $\left(r^{2}=0.77\right)$; the vehicular-based model gives the correlation $\left(r^{2}=\right.$ $0.66)$ and predicted with Quis model with input data from present study demonstrated moderate to low association, with modest predictability capacity. On the other hand the statistical $t$-test of goodness of fit reveals that the noise-based model fits the observed data with high probability while the other two models fail to fit the observed data at $5 \%$ level of significance. The summarized detail shows that all the models can predict the annoyance level within the acceptable limits in comparison to observed noise annoyance with a certain degree of error.

(iii) In the case of noise-based model, the $r^{2}$ value of 0.77 is acceptable. This model would predict the annoyance of community with better accuracy and is acceptable for this study area. This also provides evidence for the fact that annoyance among the individuals is more related to the noise levels, rather than traffic flow.

(iv) Fuzzy expert system (Table 1) and the correlation coefficient $\left(r^{2}=0.77\right)$ of noise-based models indicate that in the present study the traffic noise highly affects human work efficiency in Government offices, private organization, and commercial business centers in Agartala city.

Moreover, few important findings are summarized below, based on the study of transportation characteristics in the study area.

(i) The vehicle composition in the study area is very heterogeneous with a significant load of heavy vehicles like trucks, trailers, and buses. They produce high noise pollution and also cause traffic jams in the intersections.

(ii) Traffic management is inadequate for smooth flow of vehicles in the study area. Many intersections have no signals and those present are in nonfunctional state. Thus, manual efforts by traffic police is the only source of movement control of the vehicles. This mostly gives rise to frequent congestions and high noise pollution.

(iii) All the selected six sensitive locations are not identified by "No-Horn" or "Silence Zone" signboards.

(iv) In the absence of flyovers, all the vehicles including the heavy ones have to pass through the narrow inner town roads. The plying of the heavy-diesel powered trucks and carrier vehicles causes severe degradation of the road's edges and pavements and generates the most noise.

5.2. Analysis of the Output. From Figure 3 it is apparent that disturbances in individuals' work efficiency due to road traffic noise are a common response to almost all of them. Figure 4 shows that the road traffic noise plausibly affects human efficiency in his/her respective working places of the selected six locations at various degrees. Tables 49 also illustrate that the minimum, maximum, and the average traffic noise level at Office Lane, Mantri Bari Road, Ronaldsay Road, Akhaura Road, H.G.B. Road, and Central Road, respectively. Tables 10-13 describe expected results of 
TABLE 14: Comparison of various models using statistical analysis.

\begin{tabular}{lccc}
\hline Statistical parameters paired $t$-test $(0.05$ level $)$ & Noise-based model & Vehicular-based model & Quis model \\
\hline Mean & 27.39 & 28.48 & 1.32 \\
SD & 2.84 & 0 & 38.00 \\
Hypothesized value & 0 & 2.51 & 0 \\
$t$-statistical & 0.78 & 0.619 & 7.45 \\
$P(T \leq t)$ one tail & 0.204 & 0.66 & 4.28 \\
$r^{2}$ & 0.77 & 0.54 \\
\hline
\end{tabular}

three regression models. Statistical analysis is discussed in Table 14.

\section{Conclusion}

This research study is based on the expected relationship between traffic noise and its effect on human work efficiency in his/her respective working places. From the survey and findings it is evident that road traffic noise affects human work efficiency at Government Offices, Private Organizations, and Commercial Business Centers beside the busy main roads. Collected data were compared with the regression models developed by different sets of independent variables. The hypothesis was also tested using $t$-test in order to examine the goodness of fit between the observed annoyance level and its expected level for each of the three models separately. It can be concluded that the model based on noise indices gives a significantly acceptable high correlation coefficient values. The summarized detail shows that all the models can predict the annoyance level among the individuals' is within the acceptable limits in comparison to observed noise annoyance with a certain degree of error. The difference between the observed level of annoyance and its expected value obtained from noise-based level is not significant at $5 \%$ level. There are a number of such locations in the State Tripura facing the same problems. The present model will draw the attention of the State Government and will help the policy maker to take necessary steps to reduce this problem so that the respective works in Government Offices, Private Organizations, and Commercial Business Centers can run smoothly. The investigation technique along with the database and outputs will be helpful for the town administrator and planners for the effective traffic management and noise control in the area.

\section{References}

[1] P. A. Koushki, L. F. Cohn, and A. A. Felimban, "Urban traffic noise in Riyadh, Saudi Arabia, perceptions and attitudes," Journal of Transportation Engineering, vol. 119, no. 5, pp. 751762, 1993.

[2] E. Öhrström and A. Skånberg, "Sleep disturbances from road traffic and ventilation noise-laboratory and field experiments," Journal of Sound and Vibration, vol. 271, no. 1-2, pp. 279-296, 2004.

[3] D. Ouis, "Annoyance from road traffic noise: a review," Journal of Environmental Psychology, vol. 21, no. 1, pp. 101-120, 2001.
[4] M. Pancholy, A. F. Chhapgar, and S. P. Singa, "Noise survey in Calcutta," Journal of Scientific \& Industrial Research, vol. 26, pp. 314-316.

[5] K. Kumar and V. K. Jain, "A study of noise in various modes of transport in Delhi," Applied Acoustics, vol. 43, no. 1, pp. 57-65, 1994.

[6] G. R. Dixit, T. N. Mahadevan, and R.K. Kapoor, "A noise pollution survey of Bombay," Scavenger, vol. 122, pp. 20-25, 1982.

[7] Y. Rao, B. Y. Rao, and K. P. R. Vittal Murthy, "Traffic noise pollution at three important junctions in Visakhapatnam," Indian Journal of Environmental Protection, vol. 7, pp. 21-26, 1987.

[8] K. C. Rathore, "A noise Pollution survey of Baroda city \& its effect on human beings," Tech. Rep., IIT, New Delhi, India, 1982.

[9] D. Banerjee and S. K. Chakraborty, "Monthly variation in night time noise levels at residential areas of Asansol City (India)," Journal of Environmental Science and Engineering, vol. 48, no. 1, pp. 39-44, 2006.

[10] F. Z. Ghattas, "Assessment and analysis of Traffic Noise Pollution in Alexandria City, Egypt," World Applied sciences Journal, vol. 6, no. 3, pp. 433-441, 2009.

[11] S. Givargis and M. Mahmoodi, "Converting the UK calculation of road traffic noise (CORTN) to a model capable of calculating LAeq, $1 \mathrm{~h}$ for the Tehran's roads," Applied Acoustics, vol. 69, no. 11, pp. 1108-1113, 2008.

[12] L. A. Zadeh, "Outline of a new approach to the analysis of complex systems and decision processes," IEEE Transactions on Systems, Man and Cybernetics, vol. 3, no. 1, pp. 28-44, 1973.

[13] R. M. Tong, The Construction and Evaluation of Fuzzy Models in Advances in Fuzzy Set Theory and Applications, Edited by M. M. Gupta, R. K. Ragade, R. R. Yager, North-Holland, Amsterdam, The Netherlands, 1979.

[14] R. R. Yager and D. P. Filev, Essentials of Fuzzy Modeling and Control, John Wiley \& Sons, New York, NY, USA, 1994.

[15] E. H. Mamdani and S. Assilian, "An experiment in linguistic synthesis with a fuzzy logic controller," International Journal of Man-Machine Studies, vol. 7, no. 1, pp. 1-13, 1975.

[16] J. M. Benítez, J. L. Castro, and I. Requena, "Are artificial neural networks black boxes?" IEEE Transactions on Neural Networks, vol. 8, no. 5, pp. 1156-1164, 1997.

[17] http://www.instrumentchoice.com.au/instrument-choice/environment-meters/sl-4001-digital-sound-level-meter-mi4n.

[18] CPCB, Pollution control acts, rules, and notifications issued thereunder, Pollution control series: PCL/2/1992 (Vol. 1), New Delhi, India, Central pollution control board, 1995.

[19] A. Jamrah, A. Al-Omari, and R. Sharabi, "Evaluation of traffic noise pollution in Amman, Jordan," Environmental 
Monitoring and Assessment, vol. 120, no. 13, pp. 499-525, 2006.

[20] H. Meijer, P. Knipschild, and H. Salle, "Road traffic noise annoyance in Amsterdam," International Archives of Occupational and Environmental Health, vol. 56, no. 4, pp. 285-297, 1985. 

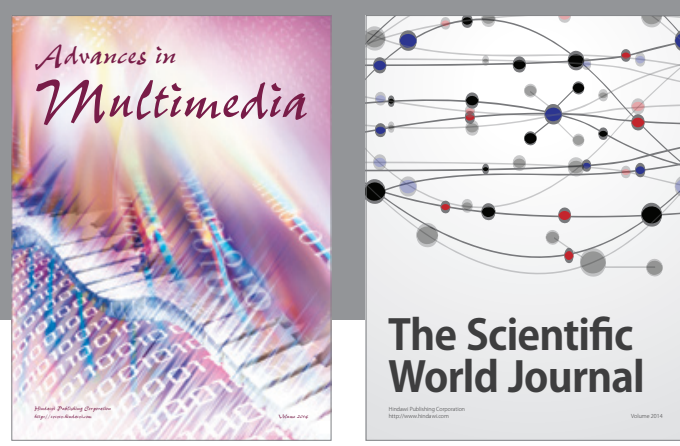

The Scientific World Journal
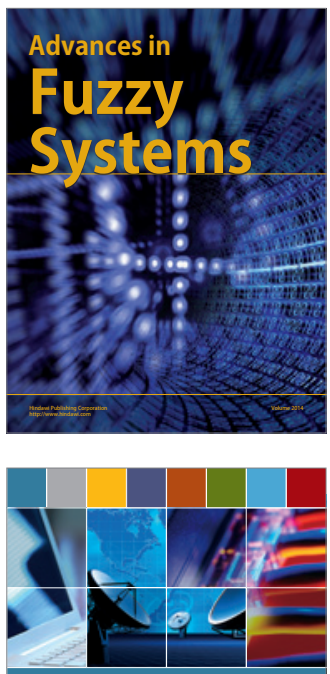

Computer Networks and Communications
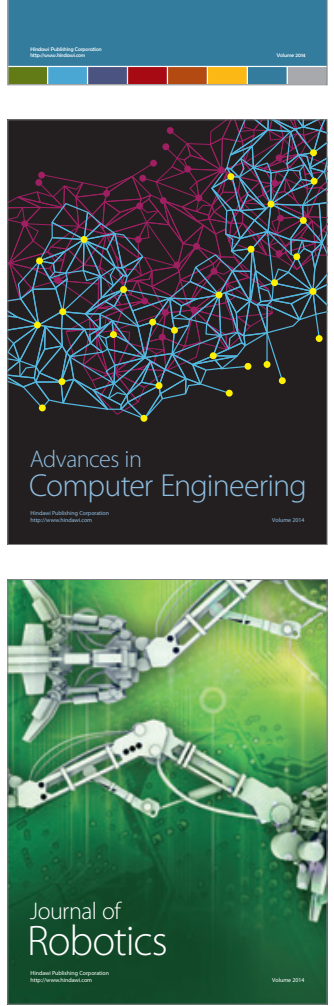
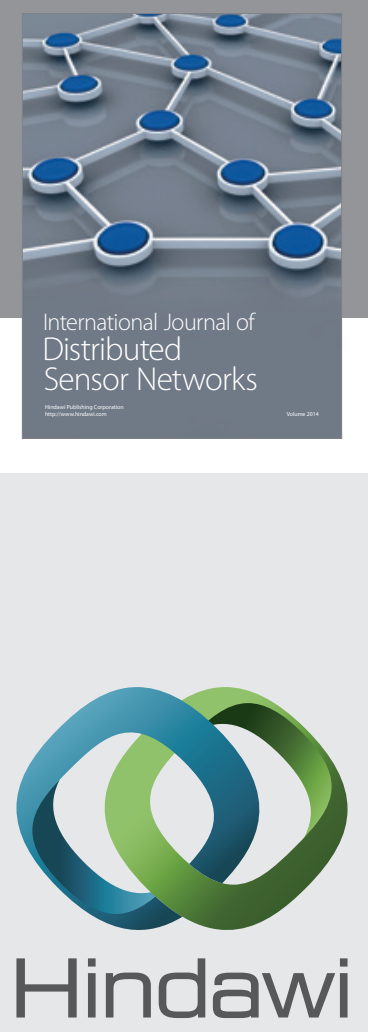

Submit your manuscripts at

http://www.hindawi.com
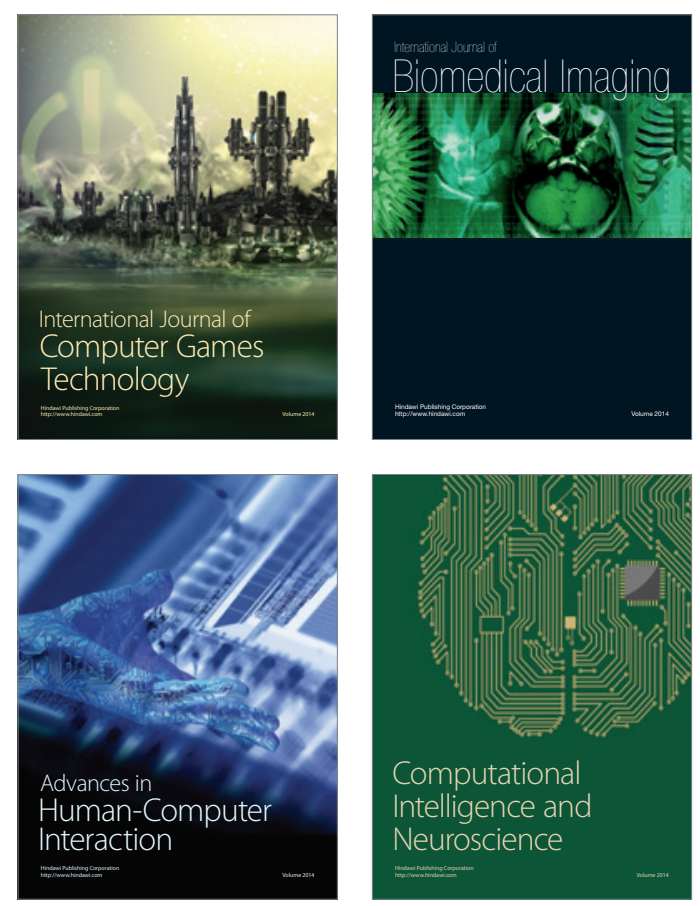
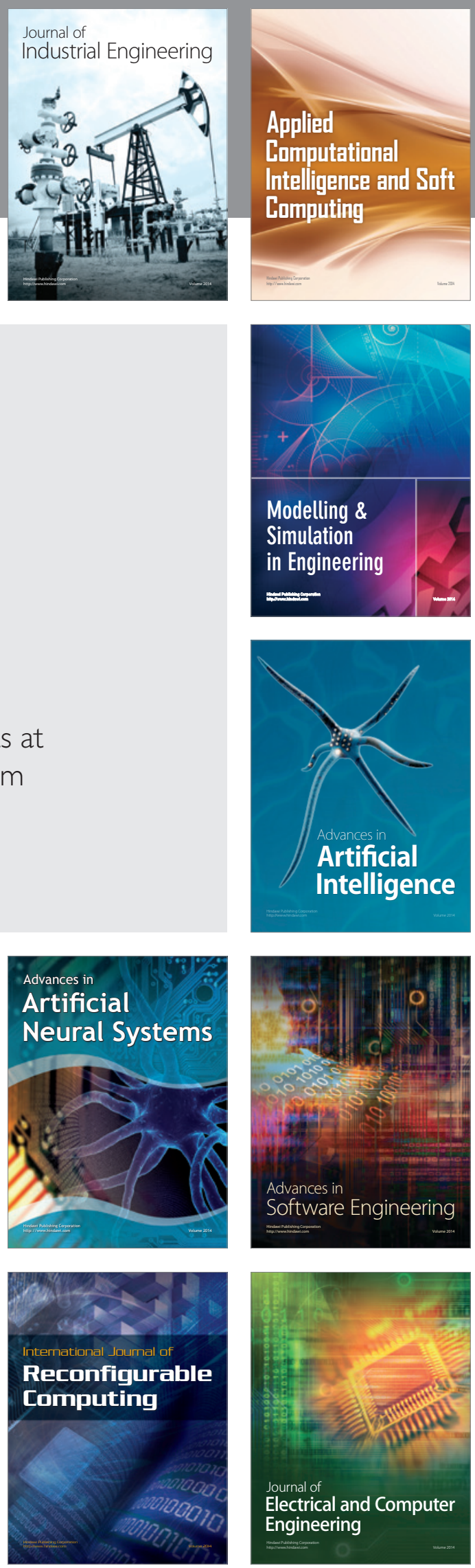